\title{
PENGARUH METODE LATIHAN AGILLITY TERHADAP KECEPATAN TENDANGAN SABIT
}

\author{
Fitri Devi Adnadia, Edi Purnomo, Mimi Haetami \\ Program Studi Pendidikan Jasmani FKIP Untan Pontianak. \\ Email: fitrideviadnadia@student.untan.ac.id
}

\begin{abstract}
The purpose of this study was to determine the effect of the Agility training method on the speed of the sickle kick at the Cuyusika Bangau Putih Pencak Silat College. This study used an experimental method with pretest and posttest treatments to determine the difference in numbers before and after being given treatment. The design used in this study was a one group pretest and posttest design. The sample in this study was the pencak silat athletes from the Cuyusika white stork college, totaling 20 athletes. The data analysis technique used is the $t$ test performed with SPSS 21 calculation which has a significance provision and an acceptance or rejection area of 5\% or 0.05 . The results showed an average pretest result of 0.34 and an average posttest result of 0.29, from an increase in kick speed from the average value of the pretest and posttest an increase of $14.71 \% "$. While the calculation of the paired sample T-Test test shows a significant number between the pretest and posttest scores. The significance value (2-tailed) $p=0.000,<0.05$, thus the null hypothesis $(\mathrm{HO})$ in this study was rejected and the alternative hypothesis ( $\mathrm{Ha}$ ) was accepted, because the significance value was smaller than 0.05. So it can be concluded that there is an effect on the agility training method on the speed of the sickle kick at the Cuyusika Bangau Putih Pencak Silat College.
\end{abstract}

Keywords: Speed, Sickle Kick, Pencak Silat

\section{PENDAHULUAN}

Olahraga merupakan bagian yang tidak terpisahkan dalam kehidupan sehari-hari di Masyarakat. Melalui olahraga dapat dilakukan pembangunan karakter suatu bangsa, sehingga olahraga menjadi sarana strategis untuk membangun kepercayaan diri, identitas bangsa, dan kebanggaan Nasional. Partisipasi dalam olahraga juga dikenal untuk mengurangi depresi, stres dan kecemasan, meningkatkan kepercayaan diri, tingkat energi, kualitas tidur, dan kemampuan untuk berkonsentrasi (Prasetyo, 2013).

Mengingat pentingnya peranan olahraga dalam kehidupan manusia, dan ikut serta dalam membentuk manusia yang berkualitas, maka pemerintah Indonesia mengadakan pembinaan dan pengembangan dibidang olahraga berupa pertandingan-pertandingan olahraga seperti atletik, sepak bola, pencak silat, bola voli, bola basket, renang, karate, futsal dan lain sebagainya. Dari sekian banyaknya jenis pertandingan yang di adakan, salah satu cabang olahraga yang cukup diminati oleh kalangan masyarakat dari yang tua hingga yang muda laki-laki hingga wanita adalah cabang olahraga Pencak Silat.
Pencak silat merupakan olahraga bela diri asli bangsa Indonesia. Berkembang sangat pesat dengan semakin banyak orang yang mempelajari pencak silat baik pribumi maupun warga negara asing. Di Indonesia sering diadakan kejuaraan-kejuaran pencak silat untuk mengetahui sejauh mana tingkat keberhasilan dari proses pelatihan yang dilakukan. Keterampilan gerak dalam olahraga pencak silat diantaranya meliputi tendangan, tangkisan, pukulan, hindaran dan jatuhan. Masing-masing teknik mempunyai fungsi dan kegunaannya sendiri.

Tendangan merupakan salah satu teknik serangan dalam olahraga pencak silat yang mempunyai nilai cukup tinggi dan merupakan salah satu teknik yang sering digunakan dalam pertandingan. Mayoritas pesilat sering menggunakan teknik tendangan sabit sebagai salah satu serangan untuk mengumpulkan poin sebanyak-banyaknya guna meraih kemenangan. 
Menurut Lubis \& Wardoyo (2014), "serangan dengan kaki atau tendangan yang dinilai adalah serangan yang masuk pada sasaran (body) menggunakan teknik serangan dengan kaki atau tendangan sabit yang bertenaga, cepat dan tepat, tidak disertai tangkapan/pegangan, dan tanpa terhalang oleh tangkisan atau elakan. Dengan demikian penulis beranggapan suatu keterampilan Teknik dasar merupakan faktor yang terpenting dalam pencapaian suatu pretasi. Meskipun masih banyak faktor-faktor yang lain, tetapi faktor keterampilan teknik dasar merupakan faktor utama dan terpenting didalam pencapaian sebuah prestasi.

Dari pengamatan tersebut muncul sebuah pemikiran bahwa hal ini disebabkan karena beberapa faktor, diantaranya disebabkan oleh faktor kondisi fisik yang mendukung terhadap tendangan sabit tersebut, pengaruh jenis kelamin atau disebabkan bentuk latihan yang selama ini dilakukan kurang mendukung atau tidak sesuai dengan tujuan dan sasaran latihan. Dengan latihan tersebut diharapkan dapat meningkatkan kemampuan kecepatan tendangan dalam pencak silat. Dalam olahraga pencak silat, teknik yang dominan dipakai adalah tendangan.

Tendangan merupakan serangan yang paling sering dipakai pada saat pertandingan oleh atlet pencak silat. Tendangan merupakan salah satu teknik yang banyak meraih keuntungan bila dibandingkan teknik pukulan. Tendangan akan menghasilkan peluang yang lebih besar untuk menciptakan poin dalam setiap pertandingan. Tendangan yang sering digunakan dalam latihan dan pertandingan adalah Tendangan Sabit.

Berdasarkan hasil Observasi yang dilakukan pada tanggal 25 april 2021 di Parindu Desa Pusat Damai dapat diketahui bahwa kecepatan atlit untuk melakukan tendangan khususnya tendangan sabit masih lambat. Proses tendangan yang lambat akan memudahkan lawan untuk menangkap tendangan yang masuk, sehingga lawan akan dengan mudah untuk melakukan proses tangkapan dan diselesaaikan dengan bantingan. Bantingan ini akan menguntungkan puhak lawan karena poin yang didapat lebih tinggi dibandingkan tendangan yang masuk. Oleh sebab itu tendangan harus dilakukan dengan secepat-cepatnya agar lawan tidak bisa menangkap tendangan yang masuk.

Berdasarkan uraian diatas, perlu adanya solusi untuk meningkatkan kecepatan tendangan sabit atlit di perguruan Cuyusika. Sadapun solusi yang diberikan penulis yaitu dengan cara memberikan latihan agillity untuk meningkatkan kecepatan tendangan sabit atlet di perguruan Cuysika. Dari latihan agillity ini diharapkan dapat meningkatkan kecepatan tendangan sabit atlet di perguruan Cuyusika.

\section{METODE PENELITIAN}

Penelitian ini menggunakan metode eksperimen. Penelitian ini menggunakan desain one grup pretest and posttest design. Menurut Sugiyono (2015:50), one grup pretest and posttest design sebagai berikut;

\section{Tabel 1}

One-Group Prestest-Posttes Desain Sugiyono, (2015)

\section{$\mathrm{O}_{1} \times \mathrm{O}_{2}$}

Keterangan:

$\mathrm{O}_{1}=$ Nilai pretest (sebelum diberi

perlakuan)

$\mathrm{O}_{2}=$ Nilai posttest (setelah diberi

perlakuan)

$\mathrm{X}=$ Treatment (perlakuan)

Sebelum di berikan treatmen atau perlakuan peneliti akan mengambil data pretest. Treatmen atau perlakuan yang diberikan yaitu berupa penggunaan metode latihan berbagai variasi agility yang dilakukan sebanyak 12 kali pertemuan. Setelah diberikan treatmen peneiti akan mengambil data posttest. Subjek dalam penelitian ini adalah atlet pencak silat cuyusika bangau putih yang berjumlah 20 orang. Instrumen dalam penelitian ini yaitu tes yang berupa tes kecepatan tendangan sabit dalam olahraga beladiri pencak silat. Adapun instrumen pelaksanaan tes dalam penelitian ini sebagai berikut:

a) Alat dan Fasilitas yaitu petching Stopwatch Meteran

b) Petugas Tes pengukuran ketinggian petching Pencatat waktu

c) Petugas Tes Pemegang petching

d) Pelaksanaan Tes kecepatan tendangan sabit Teste bersiap-siap berdiri di samping petching dengan kedua kaki berada ditengah-tengah garis. Pada abaaba "ya" test melakukan tendangan sabit kemudian berhenti dengan aba "ti", tendangan dilakukan secepatcepatnya. Pelaksanaan dapat dilakukan sebanyak satu kali dan diambil waktu 
terbaik. Pelaksanaan tes ini juga dilakukan untuk pengambilan data posttes untuk mengetahui ada atau tidaknya pengaruh latihan agillity terhadap kecepatan tendangan sabit pada

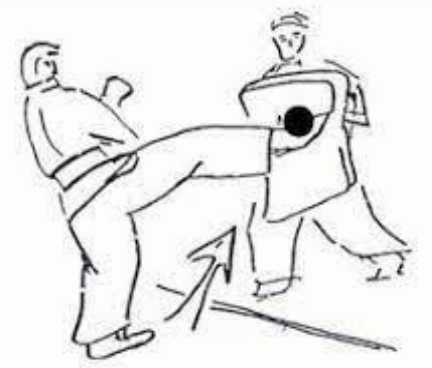

perguruan silat Cuyusika Bangau Putih.

\section{HASIL DAN PEMBAHASAN}

Hasil

Adapun statistik deskriptif dari data prestest dapat dilihat pada tabel 4.1 sebagai berikut:

Gambar 1 Tes Kecepatan Tendangan (sumber: Lubis \& Wardoyo, (2014)

Tabel 1 Hasil Pre Test Tendangan Sabit

Descriptive Statistics

\begin{tabular}{llllllll}
\hline & N & Range & Minimum & Maximum & Mean & $\begin{array}{l}\text { Std. } \\
\text { Deviation }\end{array}$ & Variance \\
\hline Pretest & 20 & .22 & .22 & .44 & .3415 & .07909 & .006 \\
\hline Valid N (listwise) & 20 & & & & & & \\
\hline
\end{tabular}

Berdasrkan perhitungan descritive statistics melalui perhitungan SPSS varian 21 diperoleh hasil rata-rata 0,34 , nilai minimum pada tabel 4.1 dari 20 jumlah sampel maka 0,22 , nilai tertinggi 0,44 , simpangan baku 0,079 dan variance 0,006 .

Tabel 2 Kategori Penilaian Kecepatan Tendangan Sabit Putri

\begin{tabular}{|c|c|c|}
\hline Kategori & Putri & Frekuensi \\
\hline Baik sekali & $<0,36$ & 3 \\
\hline Baik & $0,37-0,43$ & 1 \\
\hline Sedang & $0,44-0,50$ & 1 \\
\hline Kurang & $0,51-0,57$ & 0 \\
\hline Kurang Sekali & $>0,57$ & 0 \\
\hline \multicolumn{2}{|c|}{ Jumlah } & 5 \\
\hline $\begin{array}{l}\text { Dari tabel } 2 \text { dap } \\
\text { dari } 5 \text { sampel putri te } \\
\text { dikategorikan baik se } \\
\text { dikategorikan baik, d }\end{array}$ & $\begin{array}{l}\text { hwa } \\
\text { npel } \\
\text { npel } \\
\text { l }\end{array}$ & $\begin{array}{l}\text { dikategorikan sedang, 0 jumlah sampel } \\
\text { kurang, 0 jumlah sampel kurang sekali } \\
\text { berdasarkan data hasil pre teat yang telah di } \\
\text { ambil pada tanggal } 1 \text { mei } 2021 \text {. Sedangkan } \\
\text { untuk hasil data pretest pria sebagai berikut; }\end{array}$ \\
\hline
\end{tabular}


Tabel 3 Kategori Penilaian Kecepatan Tendangan Sabit Putra

\begin{tabular}{ccc}
\hline Kategori & Putra & Frekuensi \\
\hline Baik sekali & $<0,31$ & 5 \\
\hline Baik & $0,32-0,39$ & 4 \\
\hline Sedang & $0,40-0,48$ & 6 \\
\hline Kurang & $0,49-0,57$ & 0 \\
\hline Kurang Sekali & $>0,57$ & 0 \\
\hline & Jumlah & 15 \\
\hline
\end{tabular}

Sedangkan untuk tabel 3 dapat disimpulkan bahwa dari 15 sampel putra terdapat 5 jumlah sampel dikategorikan baik sekali, 4 jumlah sampel dikategorikan baik, dan 6 jumlah sampel dikategorikan sedang 0 jumlah sampel kurang, 0 jumlah sampel kurang sekali berdasarkan data hasil pre teat yang telah di ambil pada tanggal 1 mei 2021. Adapun statistic deskriptif data posttest dapat dilihat pada tabel 4.4 sebagai berikut:

Tabel 4 Hasil Post Test Tendangan Sabit

Descriptive Statistics

\begin{tabular}{lccccccc}
\hline & N & Range & Minimum & Maximum & Mean & $\begin{array}{l}\text { Std. } \\
\text { Deviation }\end{array}$ & Variance \\
\hline Posttest & 20 & .23 & .18 & .41 & .2920 & .07208 & .005 \\
\hline Valid N (listwise) & 20 & & & & & & \\
\hline
\end{tabular}

Adapun perhitungan descriptive statistics menggunakan SPSS varian 21 pada tabek 4.4. Adapun data dari hasil posttest menunjukan setelah diberikan treatment (perlakuan) yang berupa latihan tendangan sabit menggunakan agility kepada 20 sampel maka dapat disimpulkan dari tabel 4.4 terdapat hasil ratarata 0,29 , nilai minimum 0,18 , nilai maximum 0,41 , simpangan baku 0,072 , dan variance 0,005 .

Tabel 5 Kategori Penilaian Kecepatan Tendangan Sabit Putri

\begin{tabular}{ccc}
\hline Kategori & Putri & Frekuensi \\
\hline Baik sekali & $<0,36$ & 5 \\
\hline Baik & $0,37-0,43$ & 0 \\
\hline Sedang & $0,44-0,50$ & 0 \\
\hline Kurang & $0,51-0,57$ & 0 \\
\hline Kurang Sekali & $>0,57$ & 0
\end{tabular}


Dari tabel 5 dapat disimpulkan bahwa dari 5 sampel putri terdapat 5 jumlah sampel dikategorikan baik sekali, 0 jumlah sampel dikategorikan baik, dan 0 jumlah sampel dikategorikan sedang, 0 jumlah sampel kurang, 0 jumlah sampel kurang sekali berdasarkan data hasil preteat yang telah di ambil pada tanggal 31 mei 2021. Sedangkan untuk hasil data pretest pria sebagai berikut;

\section{Tabel 6 Kategori Penilaian Kecepatan Tendangan Sabit Putra}

\begin{tabular}{ccc}
\hline Kategori & Putra & Frekuensi \\
\hline Baik sekali & $<0,31$ & 8 \\
\hline Baik & $0,32-0,39$ & 5 \\
\hline Sedang & $0,40-0,48$ & 2 \\
\hline Kurang & $0,49-0,57$ & 0 \\
\hline Kurang Sekali & $>0,57$ & 0 \\
\hline Jumlah & & 15 \\
\hline
\end{tabular}

Dari tabel 6 dapat disimpulkan bahwa dari 15 sampel putra terdapat 8 jumlah sampel dikategorikan baik sekali, 5 jumlah sampel dikategorikan baik, dan 2 jumlah sampel dikategorikan sedang, 0 jumlah sampel kurang, 0 jumlah sampel kurang sekali berdasarkan data hasil pretest yang telah di ambil pada tanggal 31 mei 2021.
Berdasarkan analisis deskripsi data pretest dan data posttest pada tabel 4.1 dan 4.4 maka di dapat hasil rata-rata dari latihan tendangan sabit menggunakan latihan agility pada pre test adalah 0,34 sedangkan pada post test adalah 0,29 . Adapun grafik histogram hasil rata-rata pretest dan posttest dapat digambarkan sebagai berikut:

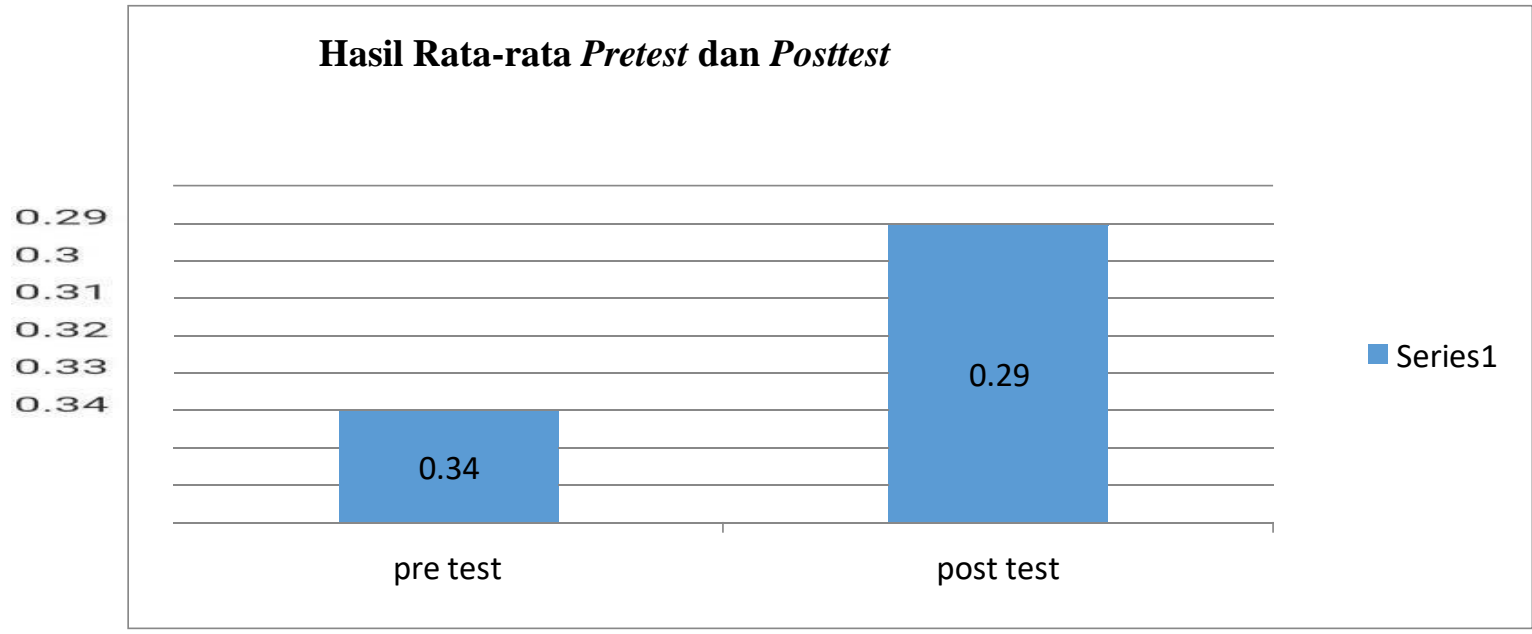

Gambar 2 Hasil Rata-Rata Nilai Pretest Dan Posttest 
Hasil uji normalitas yang dilakukan terhadap hasil tes awal (pretest) dan tes akhir (posttest) menggunakan SPSS versi 21 adalah sebagai

Tabel 8 Tes Normalitas

\begin{tabular}{ccccc}
\hline & \multicolumn{3}{c}{ Shapiro-Wilk } \\
\cline { 2 - 5 } & Statistic & Df & Sig. \\
\hline Pretest & .908 & 20 & .060 \\
\hline Posttest & .955 & 20 & .452 \\
\hline
\end{tabular}

Berdasarkan tabel 8 hasil uji normalitas untuk tendangan sabit nilai signifikan pre test $0,060>0,05$. Sedangkan nilai signifikan data post test $0,452>0,05$, dari hasil perhitungan pretest dan posttest diatas dapat disimpulkan bahwa kedua data berdistribusi normal menurut tabel 3.4, karena nilai sig kedua data lebih besar dari 0,05 .
Tujuan dari uji homogenitas adalah untuk menguji kesamaan varians antara data pretest dan data posttest. Uji normalitas ini berfungsi sebagai persyaratan dalam uji $\mathrm{T}$, dimana jika data tidak homogen maka data yang sudah didpat tidak bisa untuk di uji T. Berikut adalah hasil uji homogenitas antara prestest dan posttest:

Tabel 9 Hasil Uji Homogenitas

prepost

\begin{tabular}{ccccc}
\hline Levene Statistic & df1 & df2 & Sig. \\
\hline .281 & 1 & 38 & .599 \\
\hline
\end{tabular}

Berdasarkan hasil perhitungan homogenitas dari tabel 9 yang menggunakan SPSS varian 21 dapat disimpulkan bahwa nilai signifikannya $0,599>0,05$, artinya dari data pretest dan data post test terbukti homogen menurut tabel 3.5 karena nilai signya lebih besar dari pada 0,05 .
Adapun uji pengaruh yang dilakukan apakah hipotesis yang diajukan diterima atau ditolak yaitu dengan menggunakan analisis uji T. Berdasarkan data pretest dan posttest mendapatkan hasil penghitungan melalui SPSS varian 21 yaitu sebagai berikut;

Tabel 10 Hasil Uji-t antara Pretest dan posttest

\begin{tabular}{|c|c|c|c|c|c|c|c|}
\hline \multirow{2}{*}{ Test } & \multirow{2}{*}{$\mathbf{n}$} & \multirow{2}{*}{ Mean } & \multirow{2}{*}{$\begin{array}{l}\text { Std } \\
\text { Deviation }\end{array}$} & \multicolumn{4}{|c|}{ Paired T-Test } \\
\hline & & & & $\mathbf{T}$ & & Df & $\begin{array}{l}\text { Sig (2- } \\
\text { tailed) }\end{array}$ \\
\hline Pretest & 20 & 0,34 & 0,079 & \multirow{2}{*}{\multicolumn{2}{|c|}{7,424}} & \multirow{2}{*}{19} & \multirow{2}{*}{.000} \\
\hline Posttest & 20 & 0,29 & 0,072 & & & & \\
\hline
\end{tabular}

$*_{p}<0,005:$ nilai signifikansi

Dari tabel 10 hasil uji paired sample TTest menunjukan angka yang signifikan antara nilai pretest dan posttest. Adapun nilai signifikansi (2-tailed) $p=0.000,<0.05$, dengan demikian hipotesis (HO) pada penelitian ini ditolak dan hipotesis alternatif
(Ha) diterima menurut tabel 3.6, karena nilai signifikansi lebih kecil dari pada 0.05. Sehingga dapat disimpulkan "Ada pengaruh terhadap metode latihan agility terhadap kecepatan tendangan sabit". 


\section{Pembahasan}

Pada penelitian ini, proses pertama yang dilakukan adalah dengan mengetahui terlebih dahulu kemapuan tendangan sabit dari pesilat melalui tes awal (pretest). Adapun hasil dari tes awal (pretest) ini adalah dari 20 jumlah sampel diperoleh hasil rata-rata 0,34 , nilai minimum 0,22 , nilai tertinggi 0,44 , simpangan baku 0,079 dan variance 0,006. Dari 5 sampel putri terdapat 3 jumlah sampel dikategorikan baik sekali, 1 jumlah sampel dikategorikan baik, dan 1 jumlah sampel dikategorikan sedang. Sedangkan untuk data putra dari 15 sampel putra terdapat 5 jumlah sampel dikategorikan baik sekali, 4 jumlah sampel dikategorikan baik, dan 6 jumlah sampel dikategorikan sedang.

Selanjtnya di berikan tindakan ataupun perlakuan yaitu dengan latihan meggunakan agility yang sesuai dengan program latihan yang telah dibuat yaitu dengan 12 kali pertemuan. Setelah itu peneliti melihat perkembangan setelah diberi perlakukan terhadap kemampuan tendangan sabit, dengan melakukan tes akhir (posttest). Adapun hasil post test yang di peroleh adalah dari 20 terdapat hasil nilai rata-rata 0,29 , nilai minimum 0,18 , nilai maximum 0,41 ,

simpangan baku 0,072 , dan variance 0,005 . Dari 5 sampel putri terdapat 5 jumlah sampel dikategorikan baik sekali.

Sedangkan untuk data putra dari 15 sampel putra terdapat 8 jumlah sampel dikategorikan baik sekali, 5 jumlah sampel dikategorikan baik, dan 2 jumlah sampel dikategorikan sedang. Setelah mengetahui nilai pretest dan nilai posttes makan akan di uji normalitas, uji homogenitas, dan uji pengaruh. Adapun hasil dari uji normalitas menggunakan perhitungan SPSS varian 21 adalah nilai signifikan pretest $0,060>0,05$.

Sedangkan nilai signifikan data post test $0,452>0,05$, dari hasil perhitungan pre test dan post test diatas dapat disimpulkan bahwa kedua data berdistribusi normal menurut tabel 3.4, karena nilai signifikansi kedua data lebih besar dari 0,05. Sedangkan uji normalitas menggunakan perhitungan SPSS varian 21 dengan nilai signifikannya $0,599>0,05$, artinya dari data pre test dan data posttest terbukti homogen menurut tabel 3.5 karena nilai signya lebih besar dari pada 0,05 .
Untuk uji pengaruh hasil uji paired sample T-Test menunjukan angka yang signifikan antara nilai pretest dan post test. Adapun nilai signifikansi (2-tailed) $p=0.000$, $<0.05$, dengan demikian hipotesis (HO) pada penelitian ini ditolak dan hipotesis alternatif (Ha) diterima menurut tabel 3.6, karena nilai signifikansi lebih kecil dari pada 0.05 .

Sehingga dapat disimpulkan "Ada pengaruh yang signifikan terhadap metode latihan agility terhadap kecepatan tendangan sabit" dengan peningkatan sebelum dan sesudah diberikan perlakuan yaitu sebesar 14.71\%". Penelitian ini juga hampir sama dengan beberapa penelitian sebelumnya yang mengatakan bahwa latihan agility dapat meningkatkan kecepatan tendangan sabit sabit seseorang.

Penelitian yang dilakukan oleh Mardela (2019) mengatakan bahwa terdapat pengaruh antara latihan kelincahan dengan peningkatan kemampuan tendangan sabit atlit pencak silat Kucing Putih Harimau Campo. Penelitian yang dilakukan oleh Sinurat (2020) hasil penelitian yang diperoleh mengatakan bahwa tatihan lari Zig-Zag mempunyai pengaruh terhadap tendangan sabit pada atlit pencak silat Persaudaraan Setia Hati Terate kabupaten Rokan Hulu.

Sedangkan menurut Mihmidati \& Wahyudi (2021) terdapat sebuah peningkatan yang signifikansi dari hasil latihan agility ladder drill terhadap kelincahan tendangan sabit pencak silat Pagar Nusa Surabaya pada atlet usia remaja. Sedangkan menurut Lestiyono \& Purwono (2020), latihan agility ladder efektif digunakan untuk meningkatkan keterampilan tendangan sabit pada atlet putra Persinas Asad Semarang dari pada latihan cone drills. Sedangkan menurut Nurdin \& Indah (2021), latihan Agility Ladder memiliki pengaruh terhadap frekuensi tendangan sabit pada Pesilat Remaja Tapak Suci Kota Gorontalo.

Dari beberapa penelitian diatas dapat disimpulkan bahwa latihan agility dapat meningkatkan kecepatan tendangan seseorang. Hal ini juga didasari oleh faktor internal seperti keseriusan para pesilat dalam menjalani latihan, focus pada saat diberikan perlakuan, serta kesadaran diri para pesilat untuk datang megikuti latihan, ada juga faktor eksternal atau pengaruh dari luar seperti semanangt yang ditunjukan para pelatih serta 
motivasi dari teman-teman pesilat agar selalu rajin dan semangat menjalani setiap latihan.

\section{SIMPULAN DAN SARAN Simpulan}

Dari hasil statistik penelitian ini dapat disimpulkan bahwa terdapat pengaruh terhadap kecepatan tendangan sabit pada cabang olahraga pencak silat perguuruan Cuyusika Bangau Putih cabang Parindu sebelum dan sesudah dibeikan latihan agility. Adapun peningkatan sebelum dan sesudah diberikan perlakuan yaitu sebesar 14.71\%”.

\section{Saran}

Berdasarkan yang telah diperoleh dari penelitian ini ada beberapa saran yang dapat disampaikan : Bagi seorang atlit pencak silat hal yang paling penting adalah bagaimana cara untuk memasukan tendangan dengan secepat-cepatnya agar teandangan yang dilakukan tidak dapt ditangkap oleh lawan sehingga tidak terjadi bantingan. Bantingan adalah salah satu poin terbesar dalam pertandingan. Diharapkan pesilat atau pelatih dapat melatih tangkapan dan proses bantingan agar poin yang didapat lebih tinggi dibanding dengan tendangan yang masuk.

\section{Daftar Rujuksn}

Abdurahman, R. M., Simanjuntak, V., \& Purnomo, E. (2014). Keterampilan Gerak Dasar Tendangan Sabit Di Perguruan Pencak Silat Kijang Berantai Kota Pontianak. Jurnal Pendidikan Dan Pembelajaran Khatulistiwa, 3(6).

Kuswantokho, W., Sugito, S., \& Pratama, B. A. (2020). Hubungan Antara Kekuatan Otot Perut, Daya Ledak Otot Tungkai Dan Kelentukan Sendi Panggul Dengan Kecepatan Tendangan Sabit Pada Pesilat Persaudaraan Setia Hati Terate
Rayon Patranrejo Tahun 2020. Universitas Nusantara Pgri Kediri.

Lestiyono, D., \& Purwono, E. P. (2020). Pengaruh Latihan Agility Ladder Dan Cone Drills Terhadap Keterampilan Tendangan Sabit Pencak Silat Pada Atlet Putra Persinas Asad Semarang. Tadulako Journal Sport Sciences And Physical Education, 8(2), 74-83.

Lubis, J., \& Wardoyo, H. (2014). Pencak Silat. Rajagrafindo Persada.

Mardela, R. (2019). Pengaruh Latihan Kelincahan Terhadap Kemampuan Tendangan Sabit Atlet Pencak Silat Kuciang Putiah Harimau Campo. Jurnal Patriot, 1(1), 145-150.

Mihmidati, T., \& Wahyudi, A. R. (2021). Pengaruh Latihan Agility Ladder Drill Terhadap Kelincahan Tendangan Sabit Pencak Silat Pagar Nusa Surabaya Pada Atlet Usia Remaja. Jurnal Prestasi Olahraga, 4(9), 59-66.

Nurdin, A., \& Indah, D. (2021). Pengaruh Latihan Zig-Zag Run Terhadap Kelincahan Tendangan Sabit Atlet Pencak Silat Tapak Suci Rayon Rambah Tengah Utara. Journal Sport Rokania, 1(1), 1-7.

Prasetyo, Y. (2013). Kesadaran Masyarakat Berolahraga Untuk Peningkatan Kesehatan Dan Pembangunan Nasional. Medikora, 11(2).

Sinurat, R. (2020). Zig-Zag Run: Metode Latihan Kelincahan Tendangan Sabit Pencak Silat. Journal Sport Area, 5(2), 177-185.

Sugiyono.(2016). Metode Penelitian Kuantitatif, Kualitatif dan RnD .Bandung: Alfabeta 